Revista Iberoamericana, Vol. LXXVIII, Núms. 238-239, Enero-Junio 2012, 277-291

\title{
UN CÓCTEL CRÍTICO. UN USO DE LA CIENCIA-FICCIÓN ELABORADO POR LAS LETRAS DE ROCK PRODUCIDAS EN ARGENTINA
}

\author{
POR \\ Oscar Blanco \\ Universidad Nacional de Buenos Aires
}

Desde sus inicios, a mediados de la década del sesenta del siglo xx, en que comienzan a ser confeccionadas en lengua castellana, las letras de rock producidas en la Argentina han abreviado en diversos materiales para construir sus poéticas. La ciencia-ficción puede ser considerada una recurrencia que las atraviesa desde los comienzos; por ejemplo, desde "El despertar de un refugio atómico" (1969; Tango, 1973), de Tanguito (seudónimo de José Alberto Iglesias, 1945-1972) en la etapa inicial, pasando por "El anillo del Capitán Beto" (El jardín de los presentes, 1976), de Luis Alberto Spinetta (1950-2012), del grupo Invisible, en tiempos de dictadura, hasta "Las increíbles andanzas del Capitán Buscapina en Cybersiberia” (Ultimo bondi a Finisterre, 1998), de Patricio Rey y Los Redonditos de Ricota en los novena.

Para este trabajo ${ }^{1}$ me interesa focalizar una inflexión que se produce sobre el final de la dictadura militar y el advenimiento de las formas democráticas de gobierno en Argentina en 1983; época en que surgen nuevas tendencias en el ámbito del rock argentino, como el heavy metal o el punk, y que empieza, con bandas como Riff (1980) o Los Violadores (1983), a desplegar en sus letras un imaginario basado en películas, cómics y literatura de ciencia-ficción para conformar una denuncia de la ciudad moderna y su violencia de exclusión social en la cual se iba convirtiendo Buenos Aires y el resto de las principales ciudades Argentinas. Presentan una crítica a las políticas económicas neoliberales impuestas por la dictadura militar y luego continuadas por la democracia, al mismo tiempo que proponen una subjetividad que implica una identidad contestataria-de lo que se ve como el sistema impuesto, de la nueva ciudad moderna, de la sociedad de las nuevas máquinas, las nuevas tecnologías informáticas, las computadoras, los videos, la preeminencia de la televisión, las comunicaciones satelitales y celulares, etc.- ante el sujeto emergente a partir de esta nueva situación. Pero, previamente se deberían dar

1 El presente trabajo es parte de un libro en preparación que lleva por título: Las letras de rock en Argentina. De la caída de la dictadura a la crisis de la democracia (1983-2001). 
algunas precisiones en relación al objeto emplazado y focalizar el marco específico ubicándolo en relación al contexto histórico convocado.

El rock, como toda forma musical que implique la articulación de la palabra cantada, se conforma a partir de la intersección y de la cooperación de múltiples códigos; con el agravante, en el caso del rock, del despliegue de prácticas y espacios que son convocados para la realización de su producción, que van desde la puesta en escena en el ámbito del recital, pasando por la grabación de CD, el arte de tapa del mismo, hasta prácticas que se ubican casi exclusivamente en la instancia de recepción, como el "pogo".

Sabiendo que todo recorte de un objeto implica un cercenamiento en las posibilidades de análisis y una depresión en la instancia del sentido, convoco a una parte del complejo fenómeno rock, es decir sus letras, en tanto que instancia literaria, para focalizar en una coyuntura histórica, la que va de la caída de la dictadura en Argentina a la reanudación de la democracia en 1983, la producción de su despliegue de representación y sentido.

Las letras de rock constituyen un género discursivo y literario con estatuto propio. No son una parte u otra forma de la poesía, si bien despliegan, como todo género literario, una poética determinada en tensión y en lucha con otras poéticas del mismo campo o de campos discursivos cercanos. Las letras de rock implican su propia especificidad en la construcción del sentido. La letra de rock se escucha y esto implica una diferencia notable ante el problema de la construcción de sentido. No es, como se deja traslucir en algunos trabajos sobre la cuestión, que muy pocas letras de rock resistan una lectura en una página, colocándola en el lugar de una pobre o mediocre poesía, sino que son otra cosa, otro género discursivo distinto a la poesía; por lo tanto, mal puede trabajarse desde allí. La letra de rock implica la palabra y una voz que la articula musicalmente (no necesariamente acorde a los cánones musicales hegemónicos vigentes, sino que la mayoría de las veces, y sobre todo en el período que me ocupa, ex profeso divergente con él) y, por lo tanto, gran parte del sentido se evapora, se escurre, se pierde en su sola lectura -y ya bastante de su sentido mengua y se distorsiona al recortarla del fenómeno total del rock en donde se produce-.

En general, los escritos sobre el rock en Argentina van del contexto social a la letra de rock. El método debería ser el inverso. ¿Qué puede decir la letra de rock del contexto

2 El pogo es una práctica que compromete el cuerpo dentro del recital, fue inventado por los punks en Inglaterra, se trata de saltar rítmicamente siguiendo la música, pero empujando y ocupando el espacio del otro que está al lado, que a su vez hace lo mismo, con lo que se produce una serie de breves y continuas avalanchas que se repiten una y otra vez entrechocando los cuerpos. Esta práctica se opone tanto al baile, en la época representado por la música disco, como a la escucha en trance de los hippies; recordar que el punk surgió entre otras cosas como oposición al rock sinfónico. El pogo cambió la dinámica interna de los recitales de rock, atentando contra la instancia de constituirlo en mero espectáculo contemplativo. En la Argentina tuvo y tiene una amplia difusión que trascendió los marcos de los grupos punk ampliándose al espectro de los rockers, metálicos y rock barrial.

\footnotetext{
Revista Iberoamericana, Vol. LXXVIII, Núms. 238-239, Enero-Junio 2012, 277-291 ISSN 0034-9631 (Impreso) ISSN 2154-4794 (Electrónico)
} 
social? ¿Y de sí mismo y del propio contexto específico? Y al hablar de sí y del contexto específico, ¿qué está diciendo de lo social y cómo puede decirlo? ¿Qué relatan las letras de rock en el período propuesto? Desarrollan relatos y tópicas (y tópicos), entonces. Despliegan historias de resistencia, historias cuestionadoras, historias de adaptación a las nuevas políticas sociales. ¿Qué imaginario ponen en circulación esas historias y relatos en la representación de escenarios, en las escenas, en los personajes, en las frases que condensan una situación como un slogan y que despliegan las letras de rock? Letras que vehiculizan prácticas sociales y las propias letras de rock como prácticas sociales. La sociedad, con sus tensiones, con sus problemas, sus conflictos, pero también sus expectativas atraviesan al rock y a sus letras, extendidas en una práctica que es cultural, política, estética y musical, aglutinando sectores sociales y generacionales.

La realidad social y política está expresada en el rock argentino en la focalización sobre la vida cotidiana, en la insatisfacción y frustración urbana -hoy el rock es definitivamente una manifestación urbana, abandonada toda construcción de utopía paralela y vuelta a lo rural, a los pequeños pueblos, a las comunidades, etc.-, y todo esto sustentado la más de las veces sobre principios libertarios. ${ }^{3}$

La época que convoco se abre con una fuerte confrontación dentro del propio campo específico del rock producido en Argentina; confrontación que es síntoma, eco de una serie de controversias que se producen en lo social y en lo político ante la caída de la dictadura después de la guerra de Malvinas y el advenimiento de las instancias democráticas en los finales de 1983.

Lo que estaba instalado en el campo del rock era la denominación de rock nacional que reunía imaginariamente, en forma convergente, a sus diversas producciones. Música progresiva -con su pericia instrumental-, rock sinfónico, jazz-rock, rock comprometido o rock como canción de protesta, rock acústico, etc., distintas denominaciones que, sin embargo, se aglutinaban bajo la denominación de rock nacional. Una ética artística que se tensionaba en la oposición rock/música comercial o complaciente o decididamente música para bailar... una función social que el rock no quería para sí.

El rock nacional era un gran “marco cultural” que contenía posiciones a veces irreconciliables, pero el término nacional implicaba una imaginaria homogeneización -como en todo entronque nacionalista-que después del festival por Malvinas (16 de mayo

3 Se trata del anarquismo que se reflota en Inglaterra a partir del punk rock y que retoma la filosofía política y social que llama a la oposición y abolición de Estado entendido como gobierno, por extensión toda autoridad, jerarquía o control social de los individuos. Propende el cambio social hacia una futura sociedad sin clases y sin "amo ni soberano". Después de un declive, a mediados del siglo xx, vuelve a emerger en la década de 1960, sobre todo en Francia en el contexto de los movimientos estudiantiles antiautoritarios. En Argentina el anarquismo tiene una vasta tradición en las organizaciones obreras de principios de siglo xIx y hasta los años treinta, tal que eran la conducción de la FORA (Federación Obrera de la República Argentina), la más grande central obrera de la época.

\begin{tabular}{l} 
Revista Iberoamericana, Vol. LXXVIII, Núms. 238-239, Enero-Junio 2012, $277-291$ \\
\hline ISSN 0034-9631 (Impreso)
\end{tabular} 
de 1982), del Festival de la Solidaridad Latinoamericana, comienza a resquebrajarse. Por un lado uno de los elementos aglutinantes de esa encubierta diversidad de estilos y poéticas era la incorruptibilidad ante el sistema, el no "transar", y esto comienza a verse sospechado, a sabiendas o siendo presa, como casi todo el mundo, incluidos los partidos políticos, incluso muchos de los de izquierda, de la operación que la dictadura militar construyó con la guerra de Malvinas: lo que se denominaba rock nacional quedó pegado a dicha operación, es decir, de alguna manera terminó "transando" y nada menos que con la dictadura militar. Sin buscarlo, el rock nacional fue legitimado por el mismo sistema que lo reprimió. El recital por la guerra de Malvinas desborró los límites que el rock nacional quiso conservar en los tiempos de oscuridad impuestos por la dictadura militar: adentro del rock estaba la vida, afuera, la muerte.

Bandas nuevas u otras que empiezan a tener una visibilidad que antes no poseían comienzan a exhibir otras procedencias -rock metálico, punk, rockers, pop o new wave-, presentando un rasgo en común: oponerse a lo que estaba constituido como rock nacional y junto con ello a la contracultura en la que se basaba. Todo esto permite el cuestionamiento interno, el surgimiento de nuevas perspectivas en el campo del rock argentino que comienzan a resquebrajar hasta hacer estallar al rock nacional. Surge entonces una nueva lectura cuestionadora de la propia historia del rock y de su producción en Argentina.

Por otro lado, y tal vez a raíz de la misma problemática que se viene desplegando, toda la ideología del rock nacional comienza a ser puesta en cuestión por las bandas nuevas que ya no ocultarán la diversidad y las oposiciones internas al campo del rock producido en Argentina, sino que lo desplegarán en sus letras y en las distintas tribus urbanas que constituirán sus diversos públicos. El rock nacional con su componente contracultural es puesto en cuestión, al mismo tiempo que incluso, y sobre todo paulatinamente, las nuevas tendencias del rock viraban a posiciones decididamente políticas, separándose del proverbial apoliticismo que se había enarbolado en la etapa anterior del rock producido en argentina. El apoliticismo se transformó en apoyo a los partidos políticos en las primeras instancias eleccionarias para salir de la dictadura militar, apoyo que se tradujo primero en tocar en los festivales de campaña y después en los festivales públicos y al aire libre organizados por el radicalismo en el gobierno, y luego en el apoyo a la política de derechos humanos y a las Madres de la Plaza de Mayo en la denuncia del genocidio de los luchadores políticos y sociales. Esta participación política pasó más tarde, en la década del noventa, a la denuncia de los propios partidos políticos tradicionales, y después a la oposición de la política burguesa en general, para finalmente recobrar de diversos modos el legado político de los desaparecidos.

Lo que también empieza a ponerse en cuestión dentro del rock nacional, después de la aventura militarista de Malvinas y de la implantación de políticas económicas neoliberales que implementan la exclusión social generalizada con la pobreza y el

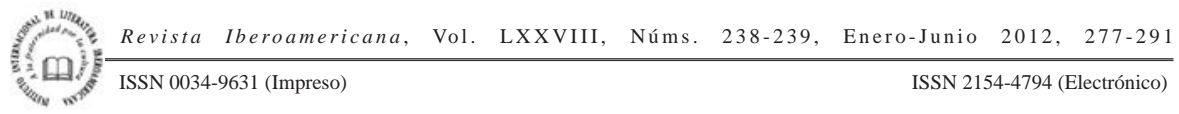


desempleo, es su postura contra toda forma de violencia, cosa que lo había distanciado de los métodos políticos de los sesenta y los setenta, incluida la guerrilla.

Un punto de inflexión, entonces, el "Festival de la Solidaridad Latinoamericana" por la guerra de Malvinas y un nuevo mapa del rock en Argentina se van a producir en los inicios de la coyuntura histórica propuesta para este trabajo.

El rock nacional se va a deshacer por profusión y exceso de estilos que se constituyen a partir de una fuerte crítica interna dentro de la especificidad del campo, por un lado, pero atentos, por otro, a la nueva situación social que se iba conformando a partir de los años de dictadura y al traspaso del gobierno militar a los partidos políticos tradicionales y las formas democráticas. De la aglutinación, necesaria ante la dictadura militar, del rock nacional, a la diversidad y dispersión de las tribus urbanas, de la imaginaria homogeneidad del rock nacional a la heterogeneidad desembozada. Divisoria de aguas que zanjaban al rock en la Argentina. Para recuperar lo político de clase, lo social y la acción social en sus letras, el rock tuvo que dejar de ser nacional. Cada nuevo grupo o banda que comienza a formarse y empieza a erosionar el rock nacional rearma la tradición y estructura sus propios linajes. Una dinámica plural en donde las tribus urbanas remarcan y despliegan en su diversificación heterogénea las contradicciones internas que el rock nacional pretendía borrar o atenuar. Las nuevas bandas proponían que el rock ya no era uno solo y se disputaba por la apropiación de su sentido, con lo cual se desplegaba a partir de ese hecho una realidad social más amplia.

Se inicia la fragmentación social de los fans y públicos del rock, y con ello también surgen las tribus urbanas y lo que fue el rock nacional se fragmenta y se desmigaja, pierde una propuesta unitaria que por imaginaria no dejó de ser efectiva. Con los inicios de la década de los ochenta comienzan a surgir, conformando su público propio, el rock metálico o pesado, el punk, los rockers, la new wave o pop (o modernos); más adelante el reggae (introducido en la Argentina por Sumo-1983-), el ska (Los Fabulosos Cadillacs -1986-), el rap y el hip hop, para nombrar las corrientes más importantes; con la aparición de las tribus urbanas y en sus diferencias se despliegan desembozadamente diferencias de clase; lo etario es lo que comienza también a desarticularse, para dar paso a políticas de clase en el rock producido en Argentina.

Frente al rock nacional aparece el rock del underground, el rock suburbano y del gueto en que comienzan a ser confinados los pobres, los sin trabajo, los excluidos. En la medida en que la guerra de Malvinas legalizó a los principales referentes del rock nacional, que ya no eran "subversivos" ni "marginales” porque eran útiles a los designios militaristas de la dictadura y a la imposición de la música en castellano en radio y televisión, como antes eran presa de la censura, es que empiezan a surgir bandas de rock que comienzan a proponerse como marginales o imbuidas del "espíritu" del underground y que después pasaran a reflejar o representar la marginación social.

\footnotetext{
Revista Iberoamericana, Vol. LXXVIII, Núms. 238-239, Enero-Junio 2012, 277-291 ISSN 0034-9631 (Impreso) 
Si durante la dictadura las letras tuvieron que articular una lengua alegórica para denunciar la vida cotidiana y la represión de Estado bajo el "Proceso" militar, el rock posterior utilizó mayoritariamente una lengua directa, callejera, no exenta de los juegos de palabras, para continuar denunciando la vida cotidiana en la democracia y su complicidad con las políticas neoliberales de exclusión social, pero también como una crítica a la representación que los medios masivos de comunicación hacían de lo social y de la misma vida cotidiana. Otra diferencia fue también entonces el pasaje de letras más herméticas o de una poética sustraída del surrealismo o formas de vanguardia ya probadas en la poesía (por ejemplo Luis Alberto Spinetta), a letras más explícitas (Los Violadores, V8, etc.), en donde el realismo se articulaba con la metáfora de factura callejera, abrevando en diversos materiales incluida la ciencia-ficción.

Desde el punto de inflexión de la caída de la dictadura militar y el advenimiento de las formas democráticas de gobierno en la década del ochenta las letras de rock despliegan, por un lado, la "deconstrucción” de los postulados sobre los que se basaba el rock nacional, y por otro lado, y a un mismo tiempo, se inicia una representación directa y una crítica política sobre lo social a partir de lo social.

Un sector de las bandas nuevas que habían comenzado a conformarse en los finales de la dictadura militar y que cobran mayor visibilidad con el advenimiento de la democracia (Riff, V8, Los Violadores) al tiempo que producen una crítica revulsiva contra el mismo campo del rock recuerdan que la lucha contra el sistema no termina con la llegada de la democracia, sino señalan que ésta continúa, quizás por otros medios (lo que empezó la dictadura militar, las políticas económicas de exclusión social, por ejemplo). La democracia, para muchos, no significó un cambio en su situación social ni tampoco en la violencia que se vive en la vida cotidiana: "de nada sirve, todo sigue igual;/ confusiones y contradicción,/ y mucha falta de comprensión./ Basta ya, no puedo soportarlo más...” (“Boff, no puedo soportarlo más”, de Riff-Pappo). Es un rock para quienes se saben actores sociales, los que empiezan a ser marginados por la democracia. Todo un sector de las nuevas propuestas del rock producido en Argentina se constituye en un ámbito cuestionador de la política gubernamental y sus efectos sociales, sobre todo para con los jóvenes.

El rock pesado y metálico -Riff, V8 (1983), y sus seguidores pertenecientes a sectores populares- se posiciona con características grupales claras ("la legión” para los seguidores de Pappo -Norberto Napolitano, 1950-2005- y de Riff; "las brigadas metálicas” para los seguidores de V8 y luego Hermética, su continuación) y asume una violencia directa contra el sistema, los autos estacionados afuera del recital, los bien vestidos, la policía, etc. De la paz contra la violencia del sistema, de la contracultura hippie del rock nacional a la violencia contra la violencia del sistema; se comienza a recuperar de otra forma el legado político de las décadas del sesenta y setenta.

El rock pesado o metálico remarcaba el origen social bajo (o mejor humilde) de músicos y público, constituyéndose en un verdadero rock proletario en los fines de la

Revista Iberoamericana, Vol. LXXVIII, Núms. 238-239, Enero-Junio 2012, 277-291
ISSN 2154-4794 (Electrónico) 
dictadura y la reanudación de las formas democráticas de gobierno, con posiciones duras y violentas; los seguidores de este estilo de rock pertenecientes a las capas más bajas de lo social, y que sabían de la pobreza, descargaban en el recital y después de él sus broncas y frustraciones sociales, lo que atraía sobre sí la mayor represión policial: "En ningún otro estilo hubo tanta influencia del índice de desocupación o de la carestía de la vida como en el rock pesado" (Pujol 183).

Riff y Pappo fueron sus referentes fundamentales en la irrupción de este estilo de rock en la Argentina. La dureza del metal aparece como oposición a la blandura de los años de la contracultura del rock nacional y la violencia contra la no-violencia y el pacifismo de los hippies: "Agresivo, sin ningún motivo;/ ya no importa, lo que puedan pensar" ("Rayo luminoso", de Pappo). Con Riff, el rock pesado rompe con el pacifismo y apela a la violencia, después de Malvinas, después de tanta represión y ataduras sociales, desde que se comienzan a hacer sentir las consecuencias de las políticas económicas neoliberales impuestas por la dictadura militar con una incipiente desocupación que sobre todo comienzan a sufrir los jóvenes de clase baja, el público preferencial del rock duro o pesado; la incitación a la violencia promovida por el rock duro de Riff, con sus cadenas y camperas negras motoqueras, implicaban un escape, un desatarse, una forma de libertad de aquel que empezaba a ser postergado y marginado: 'La paz no existe, sostienen los 'metálicos', existe la guerra y a la violencia hay que responderle con la misma moneda. Su actitud violenta es una prefiguración, un 'aviso' al sistema de lo que le espera como resultado de su propia violencia disimulada" (Vila 141). "Megáfonos recomiendan,/ use máscara de gas,/ hay oxígeno vencido/ en esta farsa de la paz" ("Pantalla del mundo nuevo", Michel Riff).

La vertiente de Riff del heavy metal despliega en sus letras un imaginario basado en un tipo de cine, el road movie, película sobre las carreteras que atraviesan grandes planicies o desiertos, típica de un tipo de cine norteamericano que pasó a ser de culto, y películas de ciencia-ficción que también transcurren en grandes carreteras, pero después de un colapso mundial de las economías basadas en las máquinas y los combustibles, de las cuales la trilogía de Mad Max (George Millar, 1979, 1981; George Millar y George Ogilvie, 1985) también se convirtió en cine de culto. Estas letras, al desplegar ese imaginario, se constituyeron en verdaderas claves alegóricas para criticar y denunciar las políticas económicas neoliberales que sólo podían ser posibles mediante la exclusión social. Como Riffse constituye en los finales de la dictadura todavía arma su poética a partir de un imaginario que es una clave para hablar de lo social en Argentina, procedimiento típico en los años de dictadura para poder eludir la censura y la persecución represiva del régimen militar (similar al caso del uso de la ciencia-ficción en Spinetta, en "El anillo del Capitán Beto”).

A partir de esta apropiación de la ciencia-ficción, la poética de Riff se articula sobre dos ejes. El primero se conforma a partir de una denuncia de la ciudad moderna y su violencia de exclusión social que va convirtiendo a Buenos Aires y el resto de las

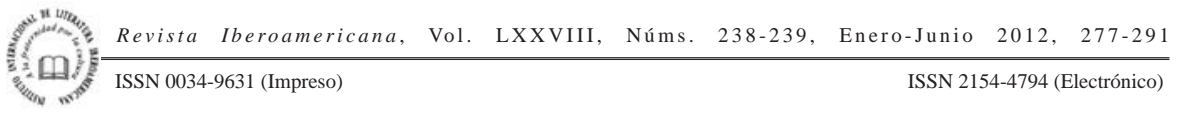


principales ciudades argentinas en una sociedad atravesada por las nuevas tecnologías (computadoras, comunicaciones satelitales, celulares, etc.) que junto con los medios de comunicación masivos, como la televisión, colocan en primer plano lo visual, produciendo así una nueva subjetividad. El segundo eje se despliega al articular un otro sujeto que se opone a ese nuevo estado de cosas. Una serie de temas, en sus letras, interrelacionan las críticas a la modernidad y la emergencia de una nueva subjetividad. "Relámpagos violetas no me dejan ver,/ la ciudad que es sólo lujuria, dinero y placer” ("Profanador de tumbas", Riff), "La ciudad del mundo nuevo/ duerme su sueño de paz,/ ve la vida en un video/ y se le va la vida, creo” ("Pantalla del mundo nuevo”, Riff). La crítica a la ciudad moderna y el advenimiento de nueva tecnología articula, por un lado, una oposición a las políticas neoliberales que trocan lo que fue la industria nacional en meras oficinas de importadores; es interesante observar que la tapa del CD editado por Riff en 1982 presenta al grupo dentro de un container o contenedor en donde llegaban las importaciones y que el disco se llame “Contenidos”, señalando esta política comenzada por la dictadura militar y continuada por la democracia como una forma de dominación. Por otro lado, esta crítica marca el advenimiento del imperio del sistema financiero en la economía, en donde el dinero y su posesión van marcando un tipo de vida en la ciudad moderna al tiempo que opera sobre una merma en las emociones que sólo comienzan a expresarse vicariamente en la contemplación de una “pantalla de video”. En el campo interno del rock que está surgiendo en esos años como oposición al rock nacional se despliega una oposición a los grupos llamados modernos (Virus -1981-, Los Twist -1983-, etc.) porque se considera que sus críticas elaboradas desde el humor y la ironía son otra forma de adaptación al sistema.

Es así que la perspectiva del estilo metálico de Riff propone una subjetividad que implica una identidad contestataria a lo que se ve como el sistema impuesto, la nueva ciudad moderna. El tema que ya en 1981 lo condensa es “Ruedas de metal”, la irrupción del motoquero argentino imbuido de una concepción anarco-nihilista, pero que establece lazos de solidaridad con los que considera sus pares: "Todo lo que tengo,/ no te lo voy a dar,/ pero compartiremos,/ por lo menos la mitad” ("Ruedas de Metal”). La subjetividad motoquera de esta vertiente de lo metálico se propone como un héroe que exhibe una violencia liberadora contra el sistema, que se traduce en "violar las reglas", "profanar" lo establecido y tensionar, llevando al extremo, lo que el sistema considera peligroso. Como en Matrimonio del cielo y del infierno (1790-3), de William Blake (1757-1827), se invierte las concepciones del bien y del mal. Un tema como "Profanador de tumbas" denuncia que lo que se constituye como el bien, la forma de vida que impone el sistema, en realidad es el mal: “y ahora en toda la gente gobierna el mal”. Las formas de vida impuestas por el sistema, primero en tanto dictadura militar, y ahora continuadas por la democracia, comienzan a internalizarse en la gente, de allí la necesidad de oponerle otra subjetividad, que en el caso de Riff implica una reacción conformada a partir de

\footnotetext{
23evista Iberoamericana, Vol. LXXVIII, Núms. 238-239, Enero-Junio 2012, 277-291 ISSN 0034-9631 (Impreso) ISSN 2154-4794 (Electrónico)
} 
un imaginario, antes descripto, proveniente de los filmes de ciencia-ficción (sobre todo Mad Max), y que es la traducción y adaptación en el medio argentino de grupos de rock metálico como, por ejemplo Motorhead. Si el sistema, encarnado en las letras de Riff por la "ciudad ultramoderna", la "ciudad del mundo nuevo", considera y ubica en el mal a todo lo que se le opone, a todo lo que lo denuncia, a toda subjetividad que intenta rebelársele, el gesto desafiante de esta subjetividad anarco-motoquera es colocarse en el lugar del mal, un mal liberador que se opone al mal que se disfraza de bien. Un héroe que persigue y espera un cataclismo final liberador contra el sistema, mientras sueña la revuelta: "Sabía que algún día el mundo iba a estallar,/ que culminaría en una destrucción total” (“La espada sagrada”, Riff). Una inflexión apocalíptica en la que la destrucción de ese mundo nuevo, encarnado en la ciudad ultramoderna, aparece como un alivio para los expulsados por ella, para los que no cuajan en ella; una expiación, una violencia punitiva sin finalidad, como la ira de Dios que es metáfora de la violencia del proletariado para Walter Benjamin, que no funda un nuevo estado de derecho, sino que destruye el establecido, inflexión anarquista en su pensamiento. ${ }^{4}$

Pero sin embargo, pese a su expresa oposición, se mantiene un resabio de la instancia contracultural del hippismo del rock nacional. La subjetividad anarco-motoquera propuesta se sostiene en una línea de fuga, un escape, una huida del sistema que denuncia, una modulación paralela y alternativa de la ciudad moderna; por supuesto que no el campo, no lo rural, sino ese otro signo de la modernidad, las grandes carreteras, las "rutas argentinas" de Almendra (Almendra II, Disco I, 1970), pero ahora de otra manera. Una “zona de nadie”, una “frontera inesperada” ("Somos de la frontera,/ que nadie imaginó” ["La frontera inesperada”, Riff]), una marginalidad conformada en la frontera de la ciudad nueva que establece un sitio sobre ella. La ciudad moderna es así, también, y al mismo tiempo es una ciudad sitiada. Si la ciudad moderna propone la propiedad privada y la propiedad volátil del dinero financiero, el imaginario desplegado en estas letras propone un nomadismo que se opone y ataca lo establecido montado en una propiedad privada móvil, la moto. Y si al principio el motoquero aparece como un héroe solitario, un guerrero (al estilo de Mad Max) que transita las carreteras atravesando planicies y desiertos, incitando a la rehabilitación de emociones e instintos originales reprimidos mediante la censura y el castigo estatal y social del sistema, muy pronto convoca a un colectivo encarnado en su público: "Hay hordas de chicos malos,/ con sus camperas de cuero,/ y metales brillan al sol,/ provocan el mundo nuevo”, "El desierto los protege/ y les presta libertad,/ les da locura su viento/ en su furioso andar" ("Pantalla del mundo nuevo", Riff). Se está ante hordas, legiones que convocan toda la parafernalia de los bárbaros asolando y sitiando la "nueva Roma”, hasta constituirse en un nosotros: "queremos seguir distintos,/ queremos agitar instintos de insatisfacción”

4 Ver al respecto Benjamin, Walter, "Para una crítica de la violencia”.

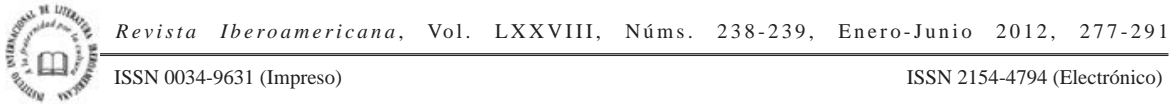


(“Maquinación”, Riff), y que sueña la revuelta, además: "Humanoides disidentes/ viven la alerta total,/ y heroicos sobrevivientes/ darán el golpe final!”, "tambalea el mundo nuevo", "La ciudad ultramoderna/ se despierta una vez más,/ no sabe que esta sitiada/ y ya no sobrevivirán” (“Pantalla del mundo nuevo”, Riff). Pero, la marginalidad propuesta a partir del imaginario descripto y desplegado en sus letras, es todavía una marginalidad elegida, tal vez empujada por el sistema, por apoyar todo lo que la subjetividad metálica constata como opresión y al rechazar todo lo que la subjetividad anarco-motoquera justamente ama.

Con la irrupción del punk en la Argentina, por ejemplo con Los Violadores, la violencia se constituye en el rock, en sus letras y en otra tribu urbana, con otra inflexión, como pura rehabilitación del instinto, una violencia con basamento en un anarquismo "tout court", sin trazas de un costado místico o apocalíptico, cuya referencia explicita es la novela La naranja mecánica (1962), de Anthony Burguess (1917-1993), y la película homónima de Stanley Kubrick (1928-1999). Si en lo trabajado hasta ahora la oposición a la contracultura emplazada en el rock nacional era contundente, con un grupo como Los Violadores que abrevan en la tradición del punk inglés de bandas como The Sex Pistols o The Clash, la opción rupturista con el rock nacional va a ser total.

La violencia había sido implacablemente ejercida desde la represión de estado y, por lo tanto, ya estaba instalada, Pil Trafa del grupo punk Los Violadores lo dice claramente ante la insistencia del periodismo de endilgarles a ellos y a su público actitudes violentas: "Todos saben quienes son los verdaderos violentos en este país. Nosotros no matamos ni encarcelamos ni torturamos a nadie” (Pujol 249). Pronto la violencia volvería a ser ejercida por el estado democrático a partir de la represión policial (“Abre la celda” y "Incomunicado”, de Todos...) ante la protesta social contra las políticas neoliberales; y el hambre, la marginalidad y la discriminación social son denunciadas como violencia sistémica por las bandas de rock más radicalizadas e incluso se extiende el concepto a las actitudes de los gobiernos democráticos: "violencia es mentir” ("Nuestro amo juega al esclavo", Patricio Rey y Los Redonditos de Ricota).

Una banda punk como Los Violadores señala las cosas sin ambagues, interpela en sus letras con brutalidad a la sociedad, de manera crítica directa, exasperada, amarga e irónica, con un lenguaje intolerante, sarcástico, que refleja el odio y la violencia que impera en la sociedad, para devolver a la sociedad una imagen de sí misma. Una manifestación colérica del dolor provocado por la asfixia de una cotidianeidad gris y opresiva al tiempo que se entabla el escándalo y la provocación dentro del rock.

Los Violadores establecen, mediante la ironía, una crítica a los estereotipos sobre lo que se suponía se asentaba la nacionalidad argentina y que venían siendo explotados por la dictadura militar como instancia publicitaria desde el Mundial de fútbol de 1978: "Hermosas tierras de amor y paz./ Hermosa gente cordialidad./ Fútbol, asado y vino/ así es el pueblo argentino”, y presentan también sus correlatos: “Censura vieja y obsoleta/

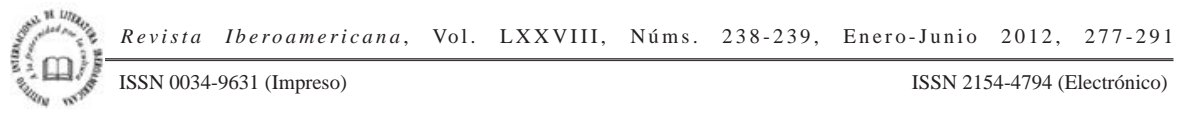


en films, revistas e historietas/ Fiestas conchetas y aburridas/ en donde está la diversión perdida" ("Represión”, Los Violadores). Desestabilizar lo nacional y el nacionalismo a partir de dos frentes, denunciar la cotidianeidad constituida a partir de los clisés -cosa que después será retomada, en otra vuelta de tuerca y en otro contexto histórico, en los inicios del siglo xxi por la Bersuit Vergarabat (1992) con el CD "La argentinidad al palo”, del 2004-, y en lo interno y específico del campo del rock, demoliendo el rock nacional a partir de una crítica feroz al hippismo y su contracultura. "Grasa hippie”, de Uno, Dos, Ultraviolento, de 1986, es un buen ejemplo de esto último: "hay cierta gente piojosa que es/ imposible nombrar/ no puedo, no puedo, no puedo/ nombrar esa basura/ producto de la inercia”, "tirados todo el día en la plaza/ quieren así el mundo cambiar/ no hay acción, no hay emoción/ solo un montón de grasa./ Dicen amar el Rock and Roll/ la progresiva y las superstars,/ evaden la realidad/ con eso, vamos hippie hacete mierda”.

Pero además denuncian la contracara de los estereotipos de la nacionalidad: "Represión a la vuelta de tu casa/ Represión en el kiosco de la esquina/ Represión en la panadería/ Represión veinticuatro horas al día/ Represión/ Represión/ Represión” ("Represión, Los Violadores), la cotidianidad está saturada de represión, represión que continuará en la democracia como forma de sostener las políticas neoliberales. Pese a que el punk en sus inicios en Argentina convocaba a bandas y público mayoritariamente de clase media (y Los Violadores no eran la excepción a esto), se denunciaba también la explotación en el mundo del trabajo como otra forma de represión, incluso comienza a denunciarse los resultados de las políticas económicas impuestas por la dictadura militar y continuadas por la instancia democrática, la desocupación en aumento: "Semanas largas sacrificadas/Trabajo duro, muy poca paga/ Desocupados no pasa nada/ ¿en dónde está, bestias,/ la igualdad deseada?” ("Represión, Los Violadores). Y es que el estilo punk, surgido en Inglaterra a partir de jóvenes de clase baja que veían incrementarse el grupo de los "parados", aunque en Argentina era un asunto de jóvenes de clase media, tenía un oído atento a la instancia de la política social de exclusión impuesta por las políticas económicas.

La inflexión de odio de clase no viene por una procedencia clasista, sino por una concepción anarquista libertaria desde la cual se denuncia y se promueve una crítica feroz contra el sistema: "ODIO a todos los patrones/ ODIO todo lo que es orden/ ODIO su falsa libertad./ No quiero todas vuestras cosas,/ No quiero sus malditas mentiras./ Sólo defenderé mi causa/ y con mi pelo rojo la amaré/ Hijos de perra miren, estoy aquí” (“Para que estoy aquí hijos de perra”, Los Violadores).

Las letras de Los Violadores al tiempo que interpelan y denuncian el sistema convocan a la acción, una acción revolucionaria incluso y sobre todo en tiempos de democracia: "estos son tiempos de acción/ Busco una sensación/ quiero una revolución” (“Tiempos de acción”, Los Violadores). Desde la articulación anarquista de sus letras todo cambio implica violencia porque del otro lado está la violencia desplegada por

\footnotetext{
Revista Iberoamericana, Vol. LXXVIII, Núms. 238-239, Enero-Junio 2012, 277-291 ISSN 0034-9631 (Impreso) ISSN 2154-4794 (Electrónico)
} 
la represión en todos los ámbitos, y porque, además, los cambios se realizan desde la recuperación de la emoción anestesiada por la inercia y desde la pasión que involucra siempre un alto grado de violencia. Y esto también articula una crítica a los modernos y a la inminente moda de la posmodernidad, donde toda pasión implica un peligro no deseado (ahí los colores fríos de las películas de David Lynch, reproducidos hasta el hartazgo por la publicidad televisiva argentina). La transformación perseguida mediante el cambio violento incide sobre tres ejes fundamentales, las emociones, la gente y el propio rock que ya se ve integrado al sistema como otro elemento de control: "Vamos a hacer/ estallar la emoción/ Vamos a tener/ que cambiar a la gente/ vamos a tener que cambiar el rock", "te escupiré/ mi colérico amor” (“Cambio violento”, Los Violadores).

La violencia, en tanto rehabilitación del instinto, implica en las letras de Los Violadores una recuperación de las emociones frente a lo que visualizan como vehículos ideológicos: los medios masivos de comunicación, sobre todo los visuales y también la música electrónica. Es decir, el despliegue de una dialéctica entre las emociones artificiales, las proporcionadas por los medios y las emociones que se consideran

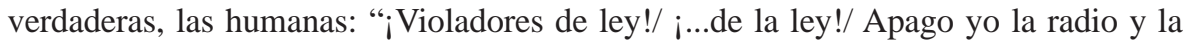
televisión/ cansado de ver filmes/ y videos del montón/ de música de máquinas/ que aplastan la emoción./ Yo quiero seguir ahora y siempre/ fuera de sektor" ("Violadores de la ley”, Los Violadores). La función liberadora de la violencia, que en La naranja mecánica desplegaba la música de Beethoven, aquí la ocupa la música de punk rock. La referencia al libro es más que clara, por ejemplo, en "Uno, dos Ultraviolento", donde se apropian del vocabulario inventado por Burguess:

Varias débochcas caminan por ahí/ mueven sus scharros con frenesí/ los málchicos de cuero nos queremos divertir/ con mis dragos al ataque vamos a ir./ ¿Y ahora qué pasa, eh?/ ¿Y ahora qué pasa, eh?/ ¿Y ahora qué pasa?, pasa:/ Uno, dos ultraviolento./ Sin militsos en la esquina es más fácil para mí/ el drencrom en la golová me hace decidir/ la de grudos más bolches la quiero para mí/ crobo rojo entre sus lapas les haremos salir./ ¿Y ahora qué pasa, eh?/ Nos quieren transformar, no lo lograrán/ no lo lograrán. No, no lo lograrán./ No, no.

Las nuevas tecnologías y máquinas, que irrumpen en la Argentina con las políticas económicas neoliberales y que desembarcan en los hogares para expandirse en nuevos mercados, implican en las letras de Los Violadores represión y otras formas de control, como una enfermedad internalizada en el sujeto que el anarquismo puede conjurar: "Programado estoy/ calibrado para su misión/ te implantan en el cráneo/ un marcapasos a presión/ del modelo represivo XHRSZ1M2./ Al terapeuta anarquista/ ahora debo ir a que extirpe el mal/ que pusieron en mí/ fueron muchos/ los golpes de represión en esta era" ("El Corregidor”, Los Violadores). Los préstamos de las películas y de los libros de ciencia-ficción, como en el último caso la novela Más que humano (1953), de

Revista Iberoamericana, Vol. LXXVIII, Núms. 238-239, Enero-Junio 2012, 277-291
ISSN 0034-9631 (Impreso) 
Theodore Sturgeon (1918-1985), son evidentes como materiales de base usados para la representación de la situación social donde es claro que las nuevas tecnologías y su importación señalan la explotación sostenida con la represión como contracara: “Ayer espejos por oro/ hoy dólares por baratijas”, "Compra y venta es el presente, el futuro lo robaron”, “Ayer espadas de traición/ hoy misiles para el terror” ("Mercado indio”, Los Violadores). El vaivén comparativo del presente con la conquista de América ubica la denuncia crítica en un orden mundial que reactualiza la categoría de imperialismo.

“Tiempos de acción”, de Los Violadores, comienza señalando que: "Es hora de encontrar/ el camino real/ vivir en la frontera/ ya no es original”. Mientras que en Riff la carretera, el desierto y las fronteras son una vía de escape de la urbe ultramoderna, en el punk representado por Los Violadores se sostiene que las fronteras son ahora internas; comienza la hora de los guetos, la urbe engendra en su interior los desiertos que son miseria. Una marginalidad contestataria dentro del campo del rock, que no propone una separación del sistema porque no hay adonde ir, enrostra su diferencia con el medio social y con lo que éste considera lo normal, comenzando un acercamiento, al menos en la representación de sus letras, con los marginados por el propio sistema, aquellos que no pueden elegir, los pobres, los desclasados, los desocupados.

Es que en la coyuntura propuesta un problema central se presenta con el futuro y la cuestión de una utopía. Mientras que la introducción de un discurso como el de la posmodernidad le era funcional a las políticas neoliberales, con la caída de los grandes relatos, el presente absoluto de la televisión y el temor al futuro; discurso que, convertido en Doxa, parecía decir: “esto es lo que tenemos”, “cuidado no pidamos más que podemos perder lo que conseguimos”, "la democracia es la utopía perseguida y ya está aquí”, posición de la cual el rock no estuvo exento, alguna vertiente del pop o de la new wave parece abrevar en ello y propagandizarlo, por ejemplo Soda Stereo (1984); desde otro sector del rock más contestatario, rockers, metálicos y punk rock, se posiciona contra esa formulación y se incita a otras postulaciones. Desde "Los héroes postergados/ desde un mañana mejor,/ ya no esperamos nada,/ porque mañana es hoy” ("La frontera inesperada”, Riff), en donde cualquier promesa de un futuro mejor, por parte del estado democrático y de la sociedad política, no podrá ser sino más de lo que se ofrece en el presente de exclusión y de retraso de los más. Continuando con: “Compra y venta es el presente,/ el futuro lo robaron”, “Compra y venta es el presente,/ el pasado lo quemaron”. ("Mercado indio", Los Violadores), en donde, sin pasado y sin futuro, queda el eterno presente posmoderno de la televisión y la versión dramática de un continuo presente de miseria en los desclasados, desocupados y marginados, quemado el pasado de lucha y de empleo, y robado el futuro sin siquiera dejar proporcionar la esperanza de una utopía. Pasando por: “¿Cómo no sentirme así?/ ¡si ese perro sigue allí!/ ¿Qué podría ser peor? (eso no me/ arregla...)/ ¡Eso no me alcanza a mí!”, “¡el futuro ya llegó!/ Llegó como vos no lo esperabas:/ todo un palo, iya lo ves!” (“Todo un palo”, Patricio Rey y Los Redonditos de Ricota), (“el futuro llegó como no lo esperabas” que no es lo mismo que

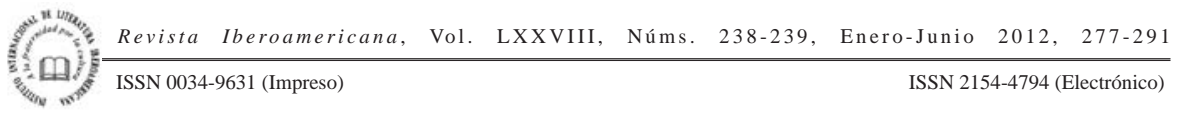


decir "no hay futuro", el Indio Solari es un rocker no un punk) en donde el vaciamiento del futuro, plegado sobre el presente, dispara el inconformismo crítico, como un arma y herramienta política, contra la resignación imperante.

Las letras de rock continuarán en los noventa, entonces, constituyéndose en una herramienta crítica contra el sistema, produciendo otros usos de la ciencia-ficción como un modo de representar un futuro a partir de una expansión y proyección crítica del presente; por ejemplo, La Renga (1991), ya que con ellos, quizás, continúa la tradición motoquera de Riff y Pappo, en la medida que a menudo sus letras presentan una inflexión apocalíptica, con paisajes que parecen extraídos de alguna añosa literatura de cienciaficción; o con Bersuit Vergarabat, en donde la ciencia-ficción es usada como denuncia del lado optimizado de las políticas neoliberales para algunos pocos; o donde un grupo como Los Brujos (1991) estructura su poética a partir de una visión cósmica, con los extraterrestres como inflexión principal. Pero eso ya es otra historia.

\section{BIBLIOGRAFÍA}

Alabarces, Pablo. Entre Gatos y Violadores. El rock nacional en la cultura argentina. Buenos Aires: Colihue, 1995.

Benjamin, Walter. Para una crítica de la violencia y otros ensayos.1921. Madrid: Taurus Humanidades, 1991.

Berti, Eduardo. Rockología. Documentos de los 80. Buenos Aires: Beas, 1994.

Blumetti, Frank y Carlos Parise. Heavy Metal argentino. Buenos Aires: Karma, 1993.

Casullo, Nicolás. “Argentina: el rock en la sociedad política”. Comunicación y Cultura 12 (1984): 41-50.

Conde, Oscar, comp. Poéticas del Rock. Vol. 2. Buenos Aires: Marcelo Héctor Oliveri, 2008.

Fernández Bitar, Marcelo. Historia del rocken Argentina. Una investigación cronológica. Buenos Aires: El Juglar, 1987.

Grinberg, Miguel. 25 años de rock nacional. Buenos Aires: Profundo, 1992.

Guerrero, Gloria. La historia del palo. Diario del rock argentino 1981-1994. Buenos Aires: La Urraca, 1995.

Kozak, Claudia. Rock en Letras. Buenos Aires: Libros del Quirquincho/Coquena, 1990.

Kreimer, Juan Carlos, Carlos Polimeni, Gustavo Álvarez Núñez y Guillermo Pintos. Ayer nomás. 40 años de rocken la Argentina. 1966-2006. BuenosAires: Musimundo, 2006.

Nadja. Las letras del rock nacional. Violadores. Buenos Aires: Amaru, 1989.

Pujol, Sergio. Rock y dictadura. Crónica de una generación (1976-1983). Buenos Aires: Emecé, 2005.

Ramos, Laura y Cynthia Lejwobicz. Corazones en Llamas. Historias del rock argentino en los 80. Buenos Aires: Clarín/Aguilar, 1991.

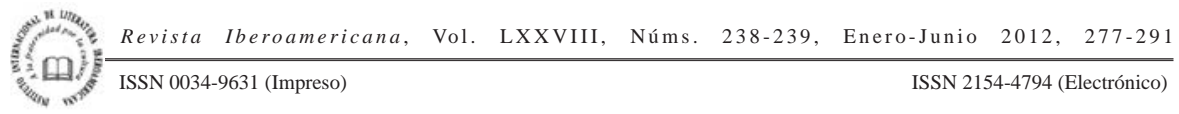


Romay, Héctor. Historia del Rock Nacional. Buenos Aires: Bureau, 2001.

Rozitchner, Alejandro. Escuchá qué tema. La filosofía del rock nacional. Buenos Aires: Planeta, 2003.

Vila, Pablo. "Rock nacional, crónicas de la resistencia juvenil”. Los nuevos movimientos sociales. Elizabeth Jelín, comp. Buenos Aires: Centro Editor de América Latina, 1985. 83-156.

\section{Discografía}

Invisible (con Luis Alberto Spinetta). "El anillo del capitán Beto”. El Jardín de los Presentes. CBS, 1976.

Tanguito (JoséAlberto Iglesias). "El despertar de un refugio atómico “. Tango. Compañía discográfica, 1973.

Todos tus muertos. “Abre la celda”. Nena de Hiroshima. Distribuidora Belgrano Norte, 1990.

"Incomunicado". Nena de Hiroshima. Distribuidora Belgrano Norte, 1990.

Patricio Rey y los Redonditos de Ricota. "Las increíbles andanzas del Capitán Buscapina en Cubersiberia”. Último bondi a Finisterre. Del Cielito Records, 1998.

“Nuestro amor juega al esclavo’. ¡Bang! ¡Bang! Estás liquidado. Del Cielito Records, 1989.

“Todo un palo”. Un baión para el ojo idiota. Del Cielito Records, 1988.

Riff. “Boff, no puedo soportarlo más”. Ruedas de Metal. Compañía discográfica, 1981. “La espada sagrada”. Riff VII. Compañía discográfica, 1985.

"La frontera inesperada”. Zona de nadie. Compañía discográfica, 1992.

“Maquinación”. Contenidos. Compañía discográfica, 1982.

"Pantalla del mundo nuevo". Contenidos. Compañía discográfica, 1982.

"Profanadordetumbas". Macadam...3...2...1...0....Compañía discográfica, 1981. "Rayo luminoso”. Ruedas de Metal. Compañía discográfica, 1981.

Los violadores. "Cambio violento”. Uno, dos, ultravioladores. Compañía discográfica, 1986.

“La era del corregidor”. Los violadores. Compañía discográfica, 1983.

Mercado indio. Compañía discográfica, 1987.

"Mercado indio". Mercado indio. Compañía discográfica, 1987.

"Para que estoy aquí (Hijos de perra)". Los violadores. Compañía discográfica, 1983.

“Represión”. Los violadores. Compañía discográfica, 1983.

“Tiempos de acción”. Fuera de sektor. Umbrales, 1986.

"Uno, dos ultraviolento”. Uno, dos, ultravioladores. Compañía discográfica, 1986.

"Violadores de la ley”. Mercado indio. Compañía discográfica, 1987.

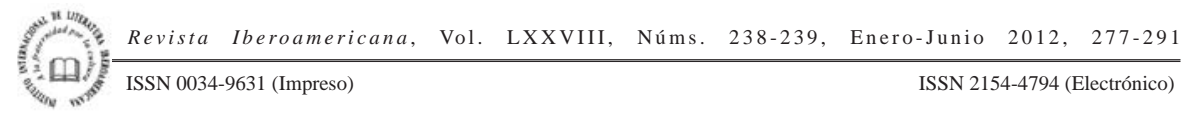


